\title{
PENSAMIENTO MERCANTILISTA Y CIRCULACIÓN MONETARIA EN EL REINO DE ARAGÓN DURANTE EL SIGLO XVII*
}

\author{
José Antonio Mateos Royo \\ Universidad de Zaragoza
}

Este artículo expone la paulatina gestación de ideas sobre acuñación y circulación monetaria en Aragón durante el siglo XVII hasta configurar un debate bien definido y de especial importancia, inserto en otro más amplio sobre la política económica del reino, en los años ochenta. A tono con la orientación práctica y limitada perspectiva del pensamiento mercantilista, las estructuras económica y política aragonesas se muestran decisivas en la configuración de este ideario. Así, los problemas monetarios y comerciales propios del reino y la Corona de Aragón situaron la discusión en términos diferentes a los planteados en Castilla. Los marcos institucional y legal aragoneses ejercieron idéntica influencia al pautar normas de actuación pública en materia monetaria distintas incluso de las adoptadas en Cataluña y Valencia. Destinadas a promover actuaciones de los organismos públicos, las propuestas de los mercantilistas aragoneses intentaron adaptarse a estos dos campos de influencia. A pesar de este esfuerzo, la falta de consenso institucional, los obstáculos de la legislación foral y el desinterés de la monarquía se revelaron obstáculos insalvables para reformar las normas de acuñación con vistas a su mejor adaptación a las transformaciones económicas acaecidas en el reino.

De acuerdo con estos objetivos, este trabajo analiza en un primer apartado los principales rasgos del declive de la economía aragonesa en el siglo XVII y su traducción en serios problemas de circulación monetaria, así como posición de las instituciones públicas sobre el tema según su distinto ideario económico. En un segundo apartado, expone el desarrollo del pensamiento mercantilista sobre

* Este trabajo se incluye en el proyecto HUM2004-00537, titulado "Absolutismo y mercado. La política del Estado, siglos XVII-XVIII" y financiado por el Ministerio de Ciencia y Tecnología. 
materia monetaria durante el Seiscientos hasta madurar en torno a las Cortes celebradas en 1677-1678 y 1684-1686. Con un claro componente arbitrista, impresos y manuscritos encierran tanto reflexiones teóricas como propuestas concretas vinculadas a las reformas monetarias adoptadas en Castilla, Valencia y Cataluña. En sintonía con su forzada adaptación a un contexto común político y económico, ambas líneas de pensamiento no sólo presentan influencias mutuas, sino comparten idéntico declive ante la perceptible falta de apoyo institucional a sus propuestas en las postrimerías de la época foral moderna.

\section{Aragón en el siglo XVII: evolución económica y circulación monetaria}

Al igual que en la Corona de Castilla, la reflexión vinculada al mercantilismo aragonés se halla presidida durante el Seiscientos por la noción de decadencia. Dirigido a las principales instituciones públicas del reino o a la monarquía, el pensamiento arbitrista repasa los problemas de una economía interior en declive y transformación. Junto a la emergencia parcial de la especialización agraria local y comarcal, esta reestructuración implicó el paulatino abandono del anterior sistema regional "autocentrado" y su mayor vinculación a otras entidades territoriales" ${ }^{1}$. Resultado de este proceso, Aragón se especializó en la producción de materias primas exportadas hacia Francia, Valencia y Cataluña, así como importó una cantidad creciente de manufacturas, Ilegadas sobre todo de Francia. Queja continua de los arbitristas, el declive industrial generó un déficit en la balanza comercial, impidió el tratamiento manufacturero de materias primas nativas como la lana y favoreció la salida de oro y plata en beneficio de Francia. El debate entre partidarios del libre cambio y del proteccionismo, que adquirió especial virulencia en Aragón entre 1674 y 1686, resulta la principal expresión de las inquietudes generadas por estos procesos en el plano del pensamiento económico.

Los primeros síntomas de declive de la economía aragonesa se aprecian a fines del siglo XVI, con especial nitidez en el estancamiento del crecimiento demográfico $^{2}$. La expulsión de los moriscos, entre un $15 \%$ y un $20 \%$ de la población aragonesa, efectuada en 1610 por orden de Felipe III agravó con rapidez este proceso. La aparición de malas cosechas y serias epidemias, así como la participación en las guerras entre España y Francia, incrementaron las defunciones en el Seiscientos. El declive económico volvió negativo en ciertos períodos el creci-

1. Torras, J., "La economía aragonesa en la transición al capitalismo. Un ensayo", Tres estudios de Historia económica de Aragón, Zaragoza, 1982, pp. 9-32 y "Relaciones económicas entre Aragón y Cataluña antes del ferrocarril", Las relaciones económicas entre Aragón y Cataluña (siglos XVIII-XX), Huesca, 1990, pp. 17-32 y Peiró, A., "Comercio de trigo y desindustrialización: las relaciones económicas entre Aragón y Cataluña", Las relaciones económicas entre Aragón y Cataluña (siglos XVIII-XX), Huesca, 1990, pp. 35-64.

2. Salas, J.A., "La evolución demográfica aragonesa en los siglos XVI y XVII", Nadal, (ed.), La evolución demográfica bajo los Austrias, Alicante, 1991, pp. 169-179. 
miento natural al descender los nacimientos y redujo la inmigración francesa. Si bien estudios recientes han moderado las pérdidas demográficas globales sufridas por Aragón durante el Seiscientos 3 , la lenta recuperación iniciada a mediados de siglo tras la gran mortalidad provocada por la peste bubónica entre 1651 y 1654 sólo demostró consolidarse en sus décadas finales.

Junto al declive demográfico, el paulatino deterioro de las haciendas públicas y nobiliarias alteró las bases de la economía asentadas durante el Quinientos. Si la nobleza aragonesa había acumulado fuertes deudas en el siglo XVI, la expulsión de los moriscos en 1610 acarreó un serio golpe al mecanismo de detracción señorial laico ${ }^{4}$. Con la intervención de la monarquía y las Cortes, las concordias entre señores y acreedores se generalizaron en el siglo XVII para pautar la gestión del patrimonio nobiliario. Las instituciones públicas aragonesas conocieron idénticas dificultades financieras ${ }^{5}$. El estancamiento de los ingresos municipales y el aumento de los gastos en la segunda mitad del Quinientos generaron un creciente déficit y una necesidad continua de préstamos. Incapaces de allegar suficientes ingresos y moderar gastos para suprimir la deuda censal o sufragar sus intereses en el Seiscientos, los concejos firmaron concordias con los censalistas que les cedían cierto control sobre la gestión de propios y arbitrios. La transmisión de la deuda censal al clero, más dispuesto a aceptar las rebajas del tipo de interés pactadas en las concordias, le confirió un mayor peso en la vida económica. Consecuencia importante, al cuestionarse los cauces habituales por este endeudamiento público y nobiliario, el sistema crediticio conoció en Aragón un fuerte deterioro.

La decadencia económica del reino halló su mejor expresión en la crisis de la producción industrial, muy marcada en la segunda mitad de la centuria ${ }^{6}$. Se ha calculado así que el número de talleres textiles descendió en Zaragoza un 51,10\% entre 1642 y 1721 y un 42,10\% en Barbastro entre 1619 y 1680 . Una encuesta efectuada por la Diputación del reino en 1667 narraba idéntica situación para otras ciudades aragonesas como Calcena, Caspe, Daroca, Alcañiz y Albarracín. Si

3. Salas, J.A., "La población aragonesa a comienzos del siglo XVIII", Ferrer (dir.), El conde de Aranda y su tiempo, Zaragoza, 2000, vol. I, pp. 355-372.

4. Abadía, A., Señorío y crédito en Aragón en el siglo XVI, Zaragoza, 1993 y La enajenación de rentas señoriales en el reino de Aragón, Zaragoza, 1998.

5. Salas, J.A., "Las haciendas concejiles aragonesas en los siglos XVI y XVII. De la euforia a la quiebra", Poder político e instituciones en la España Moderna, Alicante, 1992, pp.11-66 y Mateos, J.A., "Propios, arbitrios y comunales: la hacienda municipal en el reino de Aragón durante los siglos XVI y XVII", Revista de Historia Económica, 21/1, (2003), pp. 51-77.

6. Colas, G., "Las ciudades y la industria del reino de Aragón en los primeros años del reinado de Carlos II según diez cartas responsivas", Estudios, 74, (1974), pp. 121-129; Salas, J.A., La población de Barbastro en los siglos XVI y XVII, Zaragoza, 1981, pp. 292-294; Redondo, G., Los gremios zaragozanos del siglo XVII, Zaragoza, 1982 y "Las relaciones comerciales AragónFrancia en la Edad Moderna: datos para su estudio en el siglo XVII", Estudios, 85, (1985-86), pp. 123-154 y Peiró, A., "Comercio de trigo...", pp. 49-51 y Jornaleros y mancebos. Identidad, organización y conflicto en los trabajadores del Antiguo Régimen, Barcelona, 2002, pp. 31-41. 
bien este declive pudo favorecer cierto desarrollo de actividades artesanales en áreas rurales, la producción resultaba de baja calidad y orientada a la demanda local, incapaz de competir en mercados más amplios con las manufacturas extranjeras. La creciente orientación hacia la producción y exportación de materias primas, muy ligada a los intereses de las elites rectoras, moderó el déficit comercial y aceleró este cambio estructural en la economía aragonesa.

El continuo declive de la producción industrial y artesanal se vio precipitado por la retracción del capital mercantil aragonés a fines del siglo XVI y principios del XVII. Ejercido el control de las principales transacciones en el reino por comerciantes genoveses en 1580-1620 y franceses en adelante 7 , la recuperación de la burguesía mercantil aragonesa en la segunda mitad del Seiscientos no excluyó la presencia de comerciantes franceses y mostró una orientación más rentista y menos comercial ${ }^{8}$. Procedente en esencia del suroeste de Francia, la creciente inmigración francesa a Aragón desarrollada a partir de mediados del siglo XVI alcanzó su cenit entre 1580 y 1635 para continuar durante todo el Seiscientos. Comerciantes, mercaderes y artesanos en su mayoría, sus redes sociales apuntalaron la superioridad comercial derivada de la mejor calidad y precio de las manufacturas francesas. Al igual que las prohibiciones de extraer oro y plata hacia este país, las medidas proteccionistas de la industria aragonesa frente a las manufacturas extranjeras o discriminatorias contra los franceses residentes en territorio aragonés destinadas a reducir su presencia comercial dictadas por las Cortes se revelaron ineficaces para contener el declive comercial e industrial del reino ${ }^{10}$.

Junto a estos rasgos esenciales, la magnitud de la crisis sufrida en el siglo XVII se reflejó en la emergencia de problemas monetarios. Tras resolverse ciertas dificultades a fines de la Edad Media", el Quinientos había supuesto

7. Gómez Zorraquino, J.I., La burguesía mercantil en el Aragón de los siglos XVI y XVII, Zaragoza, 1987 y "La colonia mercantil genovesa en Aragón (1580-1620)", Homenaje a Don Antonio Durán Gudiol, Huesca, 1995, pp. 399-418.

8. Gómez Zorraquino, J.I., Zaragoza y el capital comercial. La burguesía mercantil en el Aragón de la segunda mitad del siglo XVII, Zaragoza, 1987. Como muestra de su orientación más rentista, la adquisición de tierras a nobles endeudados, la compra y arriendo de bienes inmuebles y los préstamos a la monarquía ocuparán mayor espacio en las actividades de la burguesía mercantil zaragozana durante la segunda mitad del siglo XVII.

9. Salas, J.A., "La inmigración francesa en Aragón en la Edad Moderna", Estudios, 85, (1985-86), pp. 51-77 y Langé, C., La inmigración francesa en Aragón, Zaragoza, 1993.

10. Redondo, G., Los gremios..., pp. 57-73 y "Las relaciones comerciales...", pp. 127-149.

11. Sobre las reformas monetarias de este período en Aragón, Beltrán, P., Obras Completas, Zaragoza, 1972, tomo II, pp. 448-456; Mateu, F., "El sistema monetario en Aragón. Síntesis histórica", La moneda aragonesa, Zaragoza, 1983, pp. 113-115 y Sesma, J.A., "La moneda jaquesa y la emisión de aragoneses de plata", Homenaje al doctor Antonio Beltrán Martínez, Zaragoza, 1986, pp. 1.085-1.116. Las alteraciones monetarias que afectaban a los mercados locales se aprecian con claridad en Floriano, A., "Teruel en el siglo XV. La vida económica y la cuestión monetaria", Boletín de la Real Academia de Historia, LXXXVIII, (1926), pp. 785-824 y 
una etapa de estabilidad monetaria caracterizada por la adopción en 1519 y 1528 de la ley y peso de Castilla en las piezas de plata y oro acuñadas en Aragón con objeto de favorecer los intercambios. La escasez de disposiciones públicas contrarias al empleo de monedas forasteras en el comercio, pese a su utilización efectiva, indica que su calidad intrínseca no dañaba en exceso a una creciente circulación monetaria. Sólo la salida de piezas nativas de oro y plata hacia Francia, denunciada por la legislación foral y vinculada a la menor ley de las monedas acuñadas en este territorio, anticipa los problemas venideros ${ }^{12}$. Vigente por decisión de las Cortes para estimular las transacciones con Cataluña desde 1563 hasta su derogación en 1585, la supresión de derechos aduaneros sobre aquellas piezas de oro consideradas dinero de viaje y sobre todas las monedas de plata extraídas por parte de catalanes hacia el Principado facilitó el tránsito de piezas aragonesas y castellanas de calidad hacia Francia y la llegada de moneda falsa o rebajada de peso y ley a Aragón.

Las dificultades monetarias crecieron desde inicios del Seiscientos. El déficit comercial existente en Aragón aumentó la exportación de las monedas nativas de oro y plata, en especial hacia Francia. Resultado de las relaciones comerciales y la política monetaria, el reino fue invadido bien por piezas foráneas de curso legal o por monedas nativas y extranjeras falsas -fundidas por lo común en territorios vecinos- con un menor peso y ley que las acuñaciones aragonesas. Las escasas emisiones de reales y menudos por la ceca de Zaragoza durante el siglo XVII, ligadas en el caso de la plata a la necesidad de sustituir piezas forasteras falsas o defectuosas, así como la preservación por parte de los poderes públicos en estas acuñaciones de un mayor valor intrínseco que las fabricadas en los territorios vecinos incentivaron este proceso ${ }^{13}$. Tanto los sufragios e impuestos eclesiásticos remitidos desde Aragón al Papado de Roma como las contribuciones militares, donativos y servicios cedidos a la monarquía, de especial magnitud entre 1628 y 1652, agravaron los efectos del déficit comercial y la política monetaria imperantes en el reino al disminuir la cantidad de numerario circulante, imponer una mayor utilización de

Mateos, J.A., Auge y decadencia de un municipio aragonés: el concejo de Daroca en los siglos XVI y XVII, Daroca, 1997, pp. 259-261.

12. Asso, I. de, Historia de la Economía Política en Aragón, Zaragoza, 1798, (edición facsímil, Zaragoza, 1983), pp. 276-279 y Redondo, G., "Numismática aragonesa en la Edad Moderna", La moneda aragonesa, Zaragoza, 1983, pp. 209-210. Las disposiciones monetarias de la Diputación en el Quinientos, que indican los principales problemas sobre esta materia vividos en Aragón durante la centuria, en A(rchivo) M(unicipal de) Z(aragoza), Biblioteca, Manuscrito-10, impreso sobre vedas de la moneda de oro y plata por los diputados del reino y $\mathrm{A}$ (rchivo de la) C(orona de) Aragon, $\mathrm{C}$ (onsejo de) $\mathrm{A}$ (ragon), legajo 91, prohibiciones de tránsito de moneda de plata hechas por los Diputados de Aragón, sin fechar.

13. Asso, I. de, Historia..., pp. 279-283. 
piezas forasteras y propiciar mayores adulteraciones del valor intrínseco de la moneda por parte de particulares ${ }^{14}$.

Detectadas desde comienzos del siglo XVII (1603, 1606, 1612, 1614, 1619) por parte de la Diputación del reino y en ocasiones procedentes desde Cataluña, las piezas valencianas de plata y vellón lideraron las incursiones de moneda forastera de baja ley en Aragón ${ }^{15}$. Su irrupción súbita derivó, en primer lugar, de las cuantiosas emisiones de moneda de vellón desde fines del siglo XVI (1577-81, 1595-98, 1607-14) y de plata desde principios del siglo XVII (160105 y 1616-20) realizadas por la ceca de Valencia. En segundo término, de las severas reducciones de su valor intrínseco. El vellón valenciano vio rebajada su ley en 1607 y de nuevo en 1610, esta vez junto con su peso. El real valenciano fue reducido de peso en 1611, medida que aportó fuertes beneficios a su acuñación a partir de reales castellanos, sólo moderados de forma parcial al elevarse el valor nominal de éstos en 1614. Con todo, el margen de ganancia era suficiente como para promover fuertes acuñaciones de reales por la ceca de Valencia en 1627-29 y 1641-50. Por su parte, la excesiva creación de vellón a principios de siglo y la rebaja de su peso y ley promovieron numerosas falsificaciones en el primer tercio del siglo XVII e impusieron en 1634 y 1645-47 acuñaciones más modestas.

Toda esta moneda de plata y vellón penetró con fuerza en Aragón debido a la existencia de una balanza comercial favorable en los intercambios establecidos entre el sur del territorio y el reino de Valencia, asentada sobre la necesidad constante por éste de materias primas esenciales, sobre todo trigo y carne $^{16}$. Al no saldarse su importación desde Valencia con las suficientes exportaciones, los reales dieciochenos y dineros ramillos afluían al sur de Aragón para com-

14. Colas, G. y Salas, J.A., "Las Cortes de 1626. El voto del servicio y su pago", Estudios, 75, (1975), pp. 87-139; Solano, E., Poder monárquico y estado pactista (1626-1652), Zaragoza, 1987 y Sanz, P., Política, hacienda y milicia en el Aragón de los últimos Austrias entre 1640 y 1680, Zaragoza, 1997.

15. Asso, I. de, Historia..., pp. 280-281 y Redondo, G., "Numismática aragonesa...", pp. 210-211. Sobre las acuñaciones de moneda de plata y vellón en Valencia, Hamilton, E. J., El tesoro americano y la revolución de los precios en España, 1501-1650, Barcelona, 1983, pp. 126-136 y Mateu, F., La ceca de Valencia y las acuñaciones valencianas de los siglos XIII al XVIII, Valencia, 1929, pp. 129-139.

16. Casey, J., El reino de Valencia en el siglo XVII, Madrid, 1983, pp. 81-103. La cotización del dieciocheno valenciano como dieciséis dineros en Aragón, su inferior valor intrínseco y su abundancia en el sur del reino durante la segunda mitad del siglo XVII es afirmada en Asso, I. de, Historia..., pp. 280-281 y ACA, CA, legajo 91, Informe de Jerónimo Marta, 21 de abril de 1676, legajo 1.369, no 16/1 y 2, petición de la Comunidad de Teruel sobre la utilización de la moneda valenciana, 15 de octubre de 1677 y legajo 59. Memorial de Martín de Ezpeleta, copia modificada por el autor entregada a la Diputación, sin fechar y adjuntada al anterior memorial para su remisión por el virrey, 11 de noviembre de 1692. La presencia de reales valencianos en Teruel data de la Baja Edad Media, donde ya alcanzaron a mediados del siglo XV una cotización inferior a su valor nominal. Véase Floriano, A., "Teruel...", pp. 807-809, 819-820. 
pensar este déficit, introducidos a menudo por mercaderes valencianos y con motivo de las principales ferias como las celebradas en la ciudad de Daroca. Si bien el valor intrínseco del dieciocheno se cifraba en once o doce dineros, su difusión vino favorecida por la creciente exportación de piezas de plata aragonesas y castellanas y por la aceptación de una cotización en el reino inferior a su valor nominal, aplicada sobre todo en los tratos al por mayor y fijada en dieciséis dineros durante la segunda mitad del siglo XVII. Como resultado de estos factores, los reales dieciochenos y dineros ramillos se convirtieron ya desde mediados de la centuria en la moneda de plata y vellón predominante en las comarcas de Teruel, Albarracín, Daroca y Alcañiz. Al continuar las emisiones valencianas a distinto ritmo durante la segunda mitad del Seiscientos, la persistencia del déficit comercial y el menor valor intrínseco de estas piezas favoreció su exportación a Aragón y Cataluña, así como la recepción de vellón catalán e ibicenco en Valencia a fines de la centuria ${ }^{17}$.

Frente a la omnipresente moneda valenciana, las prohibiciones de utilizar piezas catalanas dictadas por la Diputación del reino se centraron en los divinillos o ardites de vellón y tuvieron una presencia más localizada. Asociadas en ocasiones en estos bandos a otras invasiones de monedas francesas -las vaquetas del Béarn- y valencianas, su irrupción cobró auge en Aragón hacia $1620^{18}$. La causa reside en las mayores emisiones de vellón efectuadas desde 1611 por las cecas sitas en Barcelona y otros municipios catalanes ${ }^{19}$, así como en la reducción de la ley de los ardites gracias al privilegio concedido ya en 1598 por Felipe II. La carencia de numerario para sufragar el servicio concedido a Felipe IV en las Cortes de 1626 por quince años impuso en los años treinta el uso en Aragón de moneda valenciana y catalana de plata para su pago: la prohibición de la Diputación en 1632 de utilizar monedas de vellón catalanas y reales valencianos quedó así sin efecto. Tan sólo la guerra de Secesión catalana (164052) detuvo el flujo de estas piezas hacia Aragón al colapsarse las relaciones comerciales con el Principado y consolidó la fuerte presencia de la moneda valenciana $^{20}$. Si bien parte del numeroso vellón de baja ley acuñado en Catalu-

17. Mateu, F., La ceca..., pp.142-149. La perspectiva de las instituciones valencianas sobre las razones de estos flujos monetarios es analizada por el Consejo de Aragón en ACA, CA, legajo 485, doc. 38/1, Informe a su Majestad de los medios propuestos para prohibir la extracción de moneda de plata valenciana por aragoneses y catalanes, 22 de enero de 1694. Este documento confirma que la cotización citada del dieciocheno en Aragón era aceptada como un hecho común en el reino de Valencia.

18. Redondo, G., "Numismática aragonesa...", p. 211.

19. Carrera, J., Historia de la Economía española, Barcelona, 1944, tomo II, pp. 259-260, 360-361 y Vilar, P., Oro y moneda en la Historia (1450-1920), Barcelona, 1982, pp. 332-335. La importancia del privilegio concedido por Felipe II en 1598 a las cecas catalanas para acuñar vellón es reconocida en 1674 por el municipio de Zaragoza en una de sus solicitudes ante Carlos II para emitir moneda. Véase AMZ, Caja 7777, sign. 29-4, Memorial de Zaragoza a Don Juan José de Austria, 20 de noviembre de 1674.

20. Sobre el tema, véase la nota 16, Mateos, J.A., Auge y decadencia..., pp. 262-263 y Sanz, P., Política, hacienda..., pp. 138, 184. 
ña durante este conflicto circuló por Aragón durante la segunda mitad de la centuria $^{21}$, este hecho no fue considerado motivo grave de preocupación por parte de las instituciones públicas aragonesas frente a la continua absorción de dieciochenos y ramillos. Con ocasión de prohibir su uso, un bando de la Diputación dictado en abril de 1689 reconocía la introducción de estos ramillos en Aragón no sólo desde Valencia, sino desde Cataluña "y otros reinos fronterizos".

Inexistente el curso del vellón castellano en Aragón, la identidad de peso y ley entre los reales aragoneses y castellanos redujo los problemas derivados de su utilización conjunta durante el siglo XVII. Esta armonía sólo se vio turbada entre 1650 y 1654 por la llegada al reino aragonés de reales de a cuatro y a ocho acuñados en la ceca de Potosí faltos de ley²2. Los debates entre las instituciones públicas y la notable cantidad de moneda perulera fundida para acuñar reales aragoneses evidencian la fuerte penetración en el reino a mediados de la centuria de piezas acuñadas en distintas cecas del Imperio español. Facilitada por la presencia del ejército y la Corte castellanos en Aragón durante la guerra de Cataluña, esta mayor afluencia estimuló el comercio aragonés y facilitó un mayor sufragio en moneda de los servicios y contribuciones militares realizados al monarca por los municipios. Tras el cese del conflicto catalán, las piezas aragonesas y castellanas de plata tendieron a escasear en el reino frente a los más frecuentes dieciochenos valencianos durante la segunda mitad de la centuria ${ }^{23}$. Por este motivo, si bien la paridad entre los reales aragoneses y castellanos se alteró al ser devaluados éstos últimos por Carlos II durante los años ochenta, ni la Diputación ni la Junta de Brazos que estudió el tema en 1686-87 por encargo de las Cortes aragonesas dictaron ninguna disposición efectiva sobre el particular.

Vinculadas a la penetración de moneda forastera de bajo peso y ley, surgieron distintas falsificaciones de piezas nativas en el reino a lo largo de toda la centuria $^{24}$. La irrupción de moneda valenciana a principios del siglo XVII coin-

21. ACA, CA, legajo 48, memorial de Francisco Sanz de Cortes, sin fechar y A(rchivo de la) D(iputación de) Z(aragoza), manuscrito 594, 22 de abril de 1689, fols. 722r-723r.

22. Redondo, G., "La moneda perulera en Aragón (1650-1653): notas y documentos", Homenaje al doctor Antonio Beltrán Martínez, Zaragoza, 1986, pp. 1.085-1.116. Las investigaciones efectuadas por la Diputación en 1651 prueban la circulación por el territorio aragonés de reales castellanos acuñados en distintas cecas del Imperio Español como Perú, México, SeviIla y Madrid.

23. ACA, CA, legajo 48, Memoria de los procesos de ocupaciones de moneda que se pretende se sacaba a Francia (1651-1656) y legajo 76, dictamen del Consejo de Aragón disponiendo se informe al virrey sobre la falta de moneda de plata y la llegada de piezas valencianas a Aragón, 19 de julio de 1658.

24. Este proceso se puede medir a la perfección en Zaragoza en AMZ, Caja 1.562, armario 69, legajo 10, $\mathrm{n}^{\circ}$ 6, Caja 8.117, sign. 643 y Caja 8.118, sign. 670 y sign. 674; Actas Municipales, 1610, 31 de marzo, fol. 139r y 1.680, 7 de diciembre, fol. 578r, Bastardelos, $\mathrm{n}^{\mathrm{o}}$ 19, fol. 88v, $95 \mathrm{v}, 122 \mathrm{r}, 144 \mathrm{v}, \mathrm{n}^{\circ}$ 22, fol. 97v, no 24 , fol. 51r, 110r, 246v, 249r, no 33, fol. 55r, 72v, 142r, no 37 , fol. $121 r-v, n^{\circ} 40$, fol. 9v-10r y Libros de Cridas, $n^{-0} 17$, fol. 244v-248v, 257v-260r. Sus líneas generales de desarrollo se pueden constatar en otras ciudades aragonesas. Como ejemplo, Mateos, J.A., Auge y decadencia..., pp. 262-263. 
cidió con un aumento de alteraciones fraudulentas de los reales aragoneses y falsas acuñaciones de plata y vellón. La introducción desde 1610 por gascones y catalanes de numerosos reales aragoneses falsos - denominados "bosqueteros" o "bosquejos"- fabricados en el Béarn promovió en 1611 una seria intervención judicial en Zaragoza contra falsificadores, cercenadores y difusores de moneda falsa e indujo a las autoridades públicas a acuñar reales en 1611-12 y dineros en 1611-18 para intentar lograr una mayor estabilidad monetaria. Nuevas falsificaciones de menudos aragoneses se detectaron desde 1620, sobre todo entre 1626 y 1632, con motivo de introducirse en el reino moneda francesa, catalana y valenciana. Facilitadas por la baja calidad del vellón acuñado en Zaragoza en 1655-57, las falsificaciones de dineros aragoneses procedentes en esencia de Francia y Navarra se extendieron en 1660 por el reino. Una nueva emisión de moneda de vellón realizada en 1677-80 reavivó las falsificaciones en Zaragoza, hasta el punto de tener que ordenar el municipio en 1680 la quema de los menudos falsos descubiertos.

Pese a responder de forma probable a una mayor necesidad de moneda de menor valor intrínseco por parte del mercado en Aragón durante el siglo XVII y contribuir a agilizar los intercambios, todas estas alteraciones monetarias provocaron asimismo ciertos perjuicios al desarrollo del comercio que condicionaron en mucha mayor medida la política monetaria de las instituciones públicas y el pensamiento económico sobre la materia. Así, las diferencias existentes entre el valor intrínseco y el nominal de la moneda promovieron la desconfianza de la población hacia este último y dificultaron la conversión entre piezas nativas y forasteras. El déficit comercial con Francia y la invasión de monedas forasteras de menor valor intrínseco (ley de Gresham) favorecieron la exportación de las piezas aragonesas de oro y plata. Al aumentar este hecho el valor de la buena moneda nativa, sus alteraciones ilegales se tornaron más rentables. En respuesta a su mayor escasez, la moneda de oro se atesoró de forma temprana y sufrió una clara apreciación respecto a la de plata ${ }^{25}$. Con especial nitidez en la segunda mitad del siglo XVII, el acaparamiento de los reales aragoneses y castellanos se impuso en el reino hasta alcanzar a fines de la centuria incluso a los reales dieciochenos valencianos. El agio o premio pagado por la entrega de piezas de plata en vez de vellón, estimado por la Diputación durante las Cortes de 1626 para el decenio anterior en sólo un 1\% ó un 2\% de su valor, habría aumentado ya a mediados de siglo hasta el 3\% para consolidarse en la segunda mitad del Seiscientos ${ }^{26}$. En un contexto de seria recesión

25. Esta apreciación es descrita por diversos arbitristas aragoneses. Véase Asso, I. de, Historia..., p.279, Sánchez Molledo, J.M., El pensamiento arbitrista en el reino de Aragón en los siglos XVI y XVII, Madrid, 1997, (cd-rom), p. 1345 y ACA, CA, legajo 91, Memorial de Miguel Azores, sin fechar.

26. Las estimaciones de la Diputación en 1626, matizadas por su clara defensa de la libre circulación monetaria, en Carrera, J., Historia de la Economía..., tomo II, p. 416. La fijación de un agio del 3\% sobre la plata circulante en Aragón durante la segunda mitad del siglo XVII se 
económica, las falsificaciones, adulteraciones y rebajas oficiales del valor intrínseco de monedas nativas y forasteras mermaron el control público sobre el mercado y promovieron junto a otros factores procesos de inflación de precios, como el detectado en los productos artesanales durante las décadas centrales de la centuria ${ }^{27}$. Por este motivo, las autoridades aragonesas y en especial los concejos aceptaron en ocasiones pérdidas en el cambio de piezas falsas o defectuosas para intentar paliar los peores efectos de las alteraciones monetarias sobre los intercambios.

Pese a estos esfuerzos, el efecto de las alteraciones descritas se vio intensificado en Aragón por la carencia de un consenso institucional sobre política monetaria. La relativa indefinición de la normativa foral sobre fabricación de moneda y el mayor espaciamiento de las convocatorias de las Cortes aragonesas frente a la centuria anterior propiciaron que ciertos organismos intentasen asumir mayores responsabilidades sobre el tema. Patentes en los conflictos de la Diputación del reino con el virrey y el municipio de Zaragoza en 1611 y $1651^{28}$, las luchas por controlar la acuñación y circulación monetaria se agravaron al estallar las principales alteraciones y dificultaron el consenso, en especial durante la segunda mitad del Seiscientos. La existencia de distintos idearios económicos y claros enfrentamientos políticos, amén de intereses corporativos, sustentaron distintas líneas de actuación por parte de estas instituciones y restaron homogeneidad y constancia a la intervención pública ${ }^{29}$. Así, los intentos de reducir el peso y ley de la moneda aragonesa realizados por el municipio de Zaragoza en la segunda mitad del siglo XVII, en buena parte motivados por el deseo de acceder a mayores beneficios de emisión, se estrellaron siempre frente a la normativa foral y el rechazo de la Diputación. Esta institución temía que la pérdida de valor intrínseco aumentase la fuga de plata del reino, restringiese

afirma en ACA, CA, legajo 91, Informe de Miguel Pastor, 1 de enero de 1656, Informe de la Audiencia, 26 de octubre de 1660, Informe de Juan Antonio de Costas, 31 de diciembre de 1675, Informe de Jerónimo Marta, 21 de abril de 1676.

27. Mateos, J.A., Auge y decadencia..., pp. 410-419. Muchas disputas sobre esta cuestión entre el municipio de Zaragoza y distintos gremios durante el Seiscientos se hallan recogidas en Redondo, G., Los gremios..., y San Vicente, A., Documentos para una historia social y económica del trabajo en Zaragoza (siglos XV-XVIII), Zaragoza, 1988, (2 vols).

28. Asso, I. de, Historia..., p. 280; Carrera, J., Historia de la Economía..., tomo II, p. 420 y Redondo, G., "La moneda perulera...", pp. 1.088, 1.097-1.116. Sobre el tema, ACA, CA, legajos 92, 116 y 137, Informes del virrey de Aragón, la Diputación del reino y el Consejo de Aragón, enero-abril de 1651, AMZ, Actas Municipales, 1651, 16 de febrero, fol. 105v-106r, 28 de febrero, fol. 125r-126v y ADZ, Manuscrito 468, 27 y 28 de febrero de 1651, fol. 653v-673r, 17 de marzo de 1651, fol. 690v-705r y 20 de marzo de 1651, fol. 707r-709r. La oposición de la Diputación a las medidas adoptadas por otras instituciones públicas aragonesas esconde la reivindicación de su mayor concurso en las Juntas extraordinarias convocadas y presididas por el virrey para solucionar estas alteraciones monetarias.

29. Sánchez Molledo, J.M., El pensamiento arbitrista..., pp. 257-277 y ACA, CA, legajos 76, 91, 92, 106 y 198. 
el comercio y mermase los beneficios que recibía de los derechos aduaneros. La Real Audiencia de Aragón mantuvo una actitud oscilante que terminó por asumir los planteamientos de la Diputación a fines del Seiscientos. Factor determinante en esta decisión, la monarquía decidió en estos años limitar al máximo las acuñaciones de moneda aragonesa y preservar su valor intrínseco para mantener los flujos monetarios y comerciales conformados en la Corona de Aragón durante la centuria, así como para defender los beneficios derivados de los derechos de emisión adquiridos por la hacienda real en este ámbito.

\section{Aragón en el siglo XVII: pensamiento económico y circulación monetaria}

Frente a otros territorios de la Corona de Aragón, la gestación de un pensamiento económico que asumiese la necesidad de realizar serias reformas monetarias resulta más tardía en el reino aragonés. A diferencia de Cataluña y Valencia, donde las propuestas relativas a reducir el valor intrínseco de las piezas de plata y vellón cobraron fuerza desde 1610 e incluso vieron la luz de forma total o parcial ${ }^{30}$, la percepción de la conveniencia de reducir el peso y ley de la moneda tropezó en Aragón con serios obstáculos legales y le costó consolidarse. Tras una primera mitad de siglo dedicada a la comprensión de los problemas internos de circulación monetaria, la posibilidad de modificar las normas de emisión se introdujo con lentitud desde mediados de siglo gracias al interés de la monarquía y las autoridades públicas aragonesas en esta medida como fuente de beneficios. Sobre esta base, al calor de las discusiones sobre política económica generadas por la Junta Grande desde 1674 y en especial durante las Cortes de 1677-78 y 1684-86, los mercantilistas aragoneses plantearon sus iniciativas más maduras en los años ochenta. Como se observará, pese a su adaptación a la estructura política y evolución económica del reino, las dificultades impuestas por la normativa foral, la oposición de ciertas instituciones aragonesas y la falta de apoyo de la monarquía marcaron un rápido declive de estas propuestas durante la década siguiente.

Dentro del proceso de conformación de este ideario, las crecientes dificultades monetarias vividas en Aragón desde los inicios del siglo XVII provocaron reflexiones de corte tradicional. Los escritos más tempranos responden a consultas institucionales, como las realizadas por el virrey a Juan Martín Esteban en 1611 sobre la mejor forma de recaudar la moneda bosqueja de plata o por la Diputación en 1620 al doctor Baltasar Andrés y otros delegados sobre la última emisión de menudos ${ }^{31}$. En conexión con el descenso del valor intrínseco del

30. Carrera, J., Historia de la Economía..., tomo II, pp. 259-272; Hamilton, E.J., El tesoro americano..., pp. 126-136 y Vilar, P., Oro y moneda..., pp. 332-335.

31. Asso, I. de, Historia..., p. 280. Un autor anónimo recomendaba al municipio de Zaragoza en 1611 al recoger las monedas bosquejas devolver a sus propietarios sólo el valor intrínseco en vez del valor nominal como método más apropiado para acelerar el proceso de cambio 
vellón catalán y valenciano emitido a principios de la centuria, la rebaja del peso y ley de los menudos aragoneses acuñados en 1611-18 dictada por el Justicia Martín Baptista de Lanuza como maestro de la ceca de Zaragoza suscitó discusiones en el reino. Así, si los asesores de la Diputación recomendaron en 1620 mantener el peso tradicional del vellón, introdujeron la conveniencia de reducir su contenido en plata para moderar su pérdida parcial durante su acuñación y desincentivar su falsificación. Con todo, las propuestas favorables a mantener el peso y ley tradicional de las monedas aragonesas siguieron predominando ${ }^{32}$. Un autor anónimo defendía en 1617 la necesidad de acuñar piezas de plata en Aragón ante su escasez; pero se oponía a que Felipe III vendiese al municipio de Zaragoza la maestría de la ceca por temor a que éste fundiese moneda de bajo peso y ley, como -según afirmaba- había actuado en 1611-12 al fabricar reales para sustituir a la moneda bosqueja. Impresa en Zaragoza en 1625, otra propuesta anónima planteaba prohibir la entrada en el reino de doblas de oro forasteras -catalanas, flamencas- de menor valor intrínseco que las nativas y excesiva apreciación frente a la plata, así como extinguir el vellón falso en circulación y acuñar menudos y medios reales de plata con el peso y la ley vigente durante el siglo XVI.

Frente a estas primeras reflexiones ligadas a trastornos monetarios coyunturales, la convocatoria de Cortes en 1626 abrió nuevas perspectivas. Los problemas para sufragar un gravoso servicio por quince años (1628-42) y la conciencia de su envío al extranjero para costear la política belicista del conde-duque de Olivares forzaron a reconocer la progresiva carencia de buena moneda en Aragón e indagar sus causas ${ }^{33}$. Diputado en Cortes, Jerónimo Ardid señaló durante su celebración en sus "Advertencias instructivas sobre arbitrios" como principales motivos el déficit comercial con Francia y los cuantiosos sufragios destinados al Papado. Como solución, aconsejó que las Cortes sirviesen al monarca con levas de hombres en vez de dinero para evitar aumentar la exportación de plata. Medi-

de las piezas y evitar un endeudamiento excesivo de las haciendas municipales aragonesas. Véase AMZ, Caja 7.911, sign. 154-1.

32. Sánchez Molledo, J.M., El pensamiento arbitrista..., pp. 1.058-1.069. El autor del impreso publicado en 1625 evaluaba en un 5,8\% la apreciación de la dobla frente al real aragonés, así como denunciaba que la importación de estas doblas con menor valor intrínseco y de menudos falsos, unida a la concesión de un agio del $4 \%$ sobre la plata, favorecía la extracción de los reales aragoneses por mercaderes forasteros.

33. Colas, G. y Salas, J.A., "Las Cortes de 1626...". Este drenaje de moneda se vio agudizado al conceder el municipio de Zaragoza sustanciales préstamos a la monarquía durante el siglo XVII bajo la forma de censales cargados sobre su hacienda. Fueron utilizados con frecuencia por la Corona para saldar deudas bien con sus prestamistas o con los abastecedores del ejército castellano estacionado en Cataluña desde mediados de la centuria. Sobre el tema, ACA, CA, legajos 57-60, 66, 115 y 116. Estimaciones de la cuantía de estos préstamos, en Jarque, E., "El precio de la fiscalidad real: poder monárquico y oligarquía municipal en Zaragoza (16281650)"; Fortea, J.I. y Cremades, C. (eds)., Política y Hacienda en el Antiguo Régimen, Murcia, 1993, p. 338 y Sanz, P., Política, hacienda..., pp. 62-63. 
da complementaria, solicitó a Felipe IV la importación de 300.000 libras de reales o plata en pasta desde Castilla para abastecer al ejército de vituallas en Aragón, acuñar nueva moneda y reactivar la economía del reino ${ }^{34}$.

La argumentación de Ardid fue ampliada por Miguel de la Balsa en un memorial remitido a la Diputación en 1634. Este arbitrista sostenía que el pago del servicio votado en 1626 al monarca y los impuestos eclesiásticos remitidos al Papado descompensaba la balanza comercial del reino, que juzgaba equilibrada, y ocasionaban la extracción de dinero y la escasez de plata ${ }^{35}$. En una línea similar a Ardid, propuso sufragar las contribuciones reales en su totalidad en especie. Elevaba así a norma general la práctica de entregar materias primas -trigo y lana, en menor medida otros cereales, aceite, paños y cáñamo- adoptada por muchos municipios aragoneses para sufragar este servicio. Ante la falta de moneda de calidad, este sistema se prorrogará para la concesión de posteriores contribuciones y donativos a la monarquía durante el resto de la centuria ${ }^{36}$.

Junto a las reflexiones de ambos autores, que serán repetidas con frecuencia por particulares e instituciones durante la segunda mitad del Seiscientos para explicar la salida de plata ${ }^{37}$, una segunda aportación del interés durante el segundo cuarto del siglo XVII deriva de la mayor difusión de los estudios numismáticos en Aragón ${ }^{38}$. Si bien las búsquedas incluyeron el estudio de piezas anti-

34. Herranz, C., "Estudio crítico sobre los economistas aragoneses", Certamen científico y literario convocado por el Ateneo de Zaragoza, Zaragoza, 1885, pp. 129-130 y Carrera, J., Historia de la Economía..., tomo II, pp. 411-413, 426. Su discurso parece ser refrendado por las Cortes al solicitar al rey Felipe IV la petición de 200.000 libras de plata en pasta para acuñar moneda y proceder a la compra de pertrechos para el ejército, según se recoge en ACA, CA, legajo 1.358, doc. 9/1, 12 de julio de 1626. El compromiso posterior de Felipe IV ante estas Cortes de permitir la exportación anual de 150.000 libras de plata desde Castilla a Aragón con destino a la ceca de Zaragoza resultó incumplido.

35. Carrera, J., Historia de la Economía..., tomo II, pp. 432-438 y Sánchez Molledo, J.M., El pensamiento arbitrista..., pp. 1.121-1.150. El original puede consultarse en la Biblioteca de la Real Academia de la Historia, Manuscrito 9/5.703, no 10.

36. Colas, G. y Salas, J.A., "Las Cortes de 1626...", pp. 122-124; Solano, E., Poder monárquico..., pp. 54-56, 251-257 y Sanz, P., Política, hacienda..., pp. 181-183.

37. La vigencia de los argumentos de Jerónimo Ardid y Miguel de la Balsa en las discusiones sobre política monetaria de las instituciones aragonesas durante la segunda mitad del siglo XVII se aprecia en ACA, CA, legajo 91, Informe de la Audiencia, consejo civil, abril de 1676 y ADZ, Manuscrito 734, Memorial al estamento de caballeros e hidalgos, 14 de junio de 1677, fol. $69 \mathrm{r}-71 \mathrm{r}$.

38. Herranz, C., "Estudio crítico...", p. 150; Latassa, F., Bibliotecas antigua y nueva de escritores aragoneses de Latassa, aumentadas y refundidas en forma de diccionario bibliográfíco por el Dr. Miguel Gómez de Uriel, Zaragoza, 1884-1886, tomo I, p. 606 y tomo II, pp. 39, 435 y Sánchez Molledo, J.M., El pensamiento arbitrista..., pp. 251, 277. El tratado de Vicencio Juan de Lastanosa "Museo de las medallas desconocidas españolas" puede consultarse en la Biblioteca Nacional, Manuscrito 6.334, así como en la Biblioteca de la Real Academia de Historia, signatura 14/7.063. La "carta sobre el valor de la moneda jaquesa" de Jerónimo García, en la Biblioteca Nacional, Manuscrito 6.334 . 
guas y acuñaciones americanas, objeto estas últimas en 1629 de una obra manuscrita por Pedro Lupercio Ortín y Tarín, creció el interés entre los eruditos por el conocimiento de las piezas nativas vinculadas al reino de Aragón desde su origen medieval. Al margen de elaborar un estudio sobre la numismática romana, el jesuita bilbilitano Jerónimo García escribió en 1636 la "Carta sobre el valor de la moneda jaquesa" con destino al cronista del reino y numismático Francisco Jiménez de Urrea, quien redactó hacia 1640 su "Tratado sobre los florines de Aragón". En la ciudad de Huesca, Vicenzio Juan de Lastanosa y Bariz de Vera publicó en 1645 su "Museo de las medallas desconocidas españolas". Estas investigaciones sustentaron con su influencia posteriores estudios numismáticos durante la segunda mitad de la centuria para aportar una base documental sobre legislación monetaria y apreciaciones sobre el peso y ley de las distintas acuñaciones en la Corona de Aragón que fue utilizada en la polémica desatada en esencia durante los años ochenta sobre la posibilidad de reformar el valor intrínseco de la moneda jaquesa ${ }^{39}$.

Si bien la política monetaria ganó actualidad en Aragón en los años cincuenta ante la emergencia de los reales peruleros, la fuerte exportación de piezas aragonesas y castellanas y la consiguiente mayor difusión de monedas valencianas, su discusión se ciñó a las instituciones públicas ${ }^{40}$. Las necesidades financieras de la Corona ligadas a su fuerte endeudamiento resultaron esenciales para introducir en este debate hacia 1660 no sólo la conveniencia de realizar una nueva emisión y fijar su monto, sino la posibilidad de rebajar el peso y ley de las piezas de forma oficial ${ }^{41}$. Diferencia fundamental con las perspectivas adoptadas en el pasado, la evaluación de las consecuencias de estas reformas sobre la economía del reino requirió un mayor conocimiento de las actividades comerciales y la calidad de las monedas existentes en toda la Corona de Aragón.

Con todo, la necesidad de abordar una reforma monetaria no empezó a debatirse con seriedad por los arbitristas en Aragón hasta crearse la Junta Grande o de Comercio en 1674 por don Juan José de Austria durante su virreinato para buscar soluciones a problemas económicos del reino como el control comercial francés, la decadencia industrial, la falta de numerario y la despo-

39. El "Tratado sobre los florines de Aragón", manuscrito inacabado cuya redacción por Jiménez de Urrea se fecha en torno a 1640, fue utilizado por Juan Vicenzio de Lastanosa para redactar su "Tratado de la moneda jaquesa". La publicación de esta obra en Zaragoza en 1681 con el apoyo de la Diputación del reino se incardina en el debate sobre el valor intrínseco de la moneda de plata existente en Aragón. Véase Mateu, F., "Un manuscrito referente a moneda aragonesa conservado en el museo arqueológico nacional", Hispania, X, (1943), pp. 580-583 y "El sistema monetario...", pp. 126-127.

40. AMZ, Actas Municipales, 1651, 22 y 23 de marzo, fol. 155r-v y 158r-v, 1653, 7 de diciembre, fol. 635r-v, Caja 7.777, sign. 29-4 y 7.883, sign. 127-22 y ACA, CA, legajos 76, 91, 92, 106, 116, 137 y 198.

41. Véase la nota anterior. 
blación ${ }^{42}$. Los numerosos escritos dirigidos a la Junta revelan la conformación de dos líneas opuestas de pensamiento económico enfrentadas con especial vigor en la política comercial ${ }^{43}$. Los partidarios de un mayor proteccionismo como Lamberto Antonio Vidania, Manuel Ignacio Redorad y Manuel Fernández Navarro contaron con el apoyo de los municipios aragoneses, en especial de Zaragoza, influidos por la presión de los gremios ante el declive de sus manufacturas por la competencia extranjera. Representados por Marcelo Sotomayor y Urive, quien publicó en Zaragoza su "Discurso foral jurídico político en defensa de la libertad de comercio en el Reyno de Aragón" en 1675, los librecambistas hallaron su principal respaldo en la Diputación. Si bien las tesis proteccionistas parecen imponerse dentro de la Junta, la adopción final de medidas quedó remitida a las Cortes de 1677-78, cuya celebración generó un nuevo aluvión de propuestas. Las opiniones de Manuel Lasheras, Pedro Bernad, Pedro Borruel, Antonio Cubero y José Gracián, partidarios en su mayoría del proteccionismo, se cuentan entre las más autorizadas dirigidas a esta asamblea.

En este debate global sobre política económica surgen las primeras voces a favor de alterar el peso y ley de la moneda aragonesa. Dotados de cierta formación, la mayoría de los autores demuestran una escasa absorción del pensamiento mercantilista castellano en materia monetaria, cuyos principales representantes no son citados en sus trabajos ${ }^{44}$. Ante la mayor similitud de sus instituciones y problemas monetarios, las medidas adoptadas en Valencia y Cataluña suponen una clara referencia. Con todo, la propia observación de procesos económicos en el reino o la experiencia derivada de sus viajes al extranjero son las fuentes principales utilizadas en sus escritos sobre el tema ${ }^{45}$. Sus apreciaciones sobre usos monetarios se hallan subordinadas a sus idearios sobre política comercial, de marcado signo proteccionista en Cubero, Borruel, Tudela Tarazona o Gracián Serrano, presentados bien ante la Junta de Comercio o las Cortes aragonesas para promover reformas legislativas. Pese al deseo de reafirmar la autarquía económica e identidad política del reino al desterrar las piezas forasteras, sus medidas monetarias muestran un escaso desarrollo al constituirse en mero fin

42. Asso, I. de, Historia..., p. 237. Sobre los problemas económicos de Aragón tratados por esta Junta, consúltese en la Biblioteca Nacional de Madrid, Manuscrito 9.825, Lezaún, T.F., Apuntaciones históricas sacadas de los registros de actos comunes de los diputados del reino de Aragón, desde 1469 hasta 1707 en que se extinguió el Consistorio tomo V, fol. 18v-20r (inédito).

43. Asso, I. de, Historia..., pp. 237-238. Sobre los representantes de estas dos distintas concepciones del pensamiento y la política económica existentes en el Aragón del Seiscientos, Sánchez Molledo, J.M., "Pensamiento aragonés sobre el comercio exterior en el siglo XVII: los arbitristas", Cuadernos aragoneses de economía, 8, 1, (1998), pp. 59-72.

44. Esta escasez de referencias a otros autores, pese a utilizar en ocasiones sus escritos, es un rasgo muy característico del pensamiento mercantilista en la Europa Moderna. Véase Perdices, L. y Reeder, J., El mercantilismo: política económica y Estado nacional, Madrid, 1998, p. 20.

45. Sobre la extracción social, formación viajera y motivaciones de los mercantilistas aragoneses del Seiscientos, Sánchez Molledo, J.M., "Arbitristas aragoneses en el siglo XVII", Torre de los Lujanes, 38, (1999), pp. 232-236. 
para lograr una balanza comercial más equilibrada. Desligado de esta corriente, sólo Manuel Lasheras alcanza un mayor grado de reflexión teórica al englobar sus reformas de las emisiones aragonesas una severa crítica a la política monetaria practicada por la monarquía en las Coronas de Castilla y Aragón, así como al mostrar la influencia de autores castellanos. Nota destacada, los arbitristas aragoneses centran su atención en la moneda de oro y sobre todo en la plata, de acuerdo con la estimación general otorgada por el mercantilismo a la acumulación de metales preciosos para consolidar la economía de todo territorio. Al haber sufrido en Aragón menores alteraciones que en la Corona de Castilla por parte de los poderes públicos ${ }^{46}$, el vellón recibe mucha menos atención en sus memoriales. Por este motivo, frente a los mercantilistas castellanos, sus propuestas de devaluar el real aragonés a menudo olvidan o marginan la conveniencia de readaptar las relaciones de equivalencia con las piezas de inferior ley, como los dineros o menudos de vellón, mediante la alteración de su valor nominal.

Con estas premisas, el problema monetario ganó actualidad ante las denuncias de los economistas aragoneses proteccionistas sobre las malas consecuencias que tenía la extracción de oro y plata del reino ${ }^{47}$. Su fin último era implantar una legislación que evitase la entrada de manufacturas extranjeras, en especial de Francia, y la salida de metales preciosos para saldar el déficit comercial. En un memorial remitido a las Cortes en 1678, Pedro Borruel describió la fundición de piezas aragonesas presenciada en ciudades francesas (París, Lyon, Bayona, Burdeos, Tolosa, Montpellier, Marsella, Aviñón), para su acuñación como moneda propia tras ser obtenidas por comerciantes franceses en Aragón mediante la cesión de un agio en sus transacciones. Tanto Pedro Borruel en 1678 como José Tudela Tarazona en 1684 insistieron ante las instituciones aragonesas en que la inclusión de una mayor cantidad de cobre en los luises fabricados con piezas españolas rendía grandes beneficios a Francia y en especial a su monarca. Este proceder no sólo restaba metales preciosos a Aragón, sino facilitaba su sustitución por piezas de menor valor intrínseco, muchas falsas o cortadas. Consecuencia de su mayor escasez, Antonio Cubero Sebastián y José Gracián Serrano constataron la apreciación del oro sobre la plata en Aragón en la segunda mitad del siglo XVII, cifrada en un 7,7\% para el escudo aragonés y un $8,7 \%$ para el doblón castellano frente al real aragonés.

46. García Guerra, E.M., Las acuñaciones de moneda de vellón durante el reinado de Felipe III, Madrid, 1999; Serrano Mangas, F., Vellón y metales preciosos en la Corte del rey de España (1618-1668), Madrid, 1996; Santiago Fernández, J., Política monetaria en Castilla durante el siglo XVII, Valladolid, 2000; Domínguez Ortiz, A., Política y hacienda de Felipe IV, Madrid, 1983, pp. 237-264; Hamilton, E.J., El tesoro americano..., pp. 87-115; Collantes, E. y Merino, J.P., "Alteraciones al sistema monetario de Castilla durante el reinado de Carlos II", Cuadernos de Investigación Histórica, 1, (1977), pp. 73-98 y García de Paso, J.I., "La estabilización monetaria en Castilla bajo Carlos II", Revista de Historia Económica, 18, 1, (2000), pp. 49-77.

47. Asso, I. de, Historia..., pp. 277-279 y Sánchez Molledo, J.M., El pensamiento arbitrista..., pp. 1.345, 1.379, 1.419-1.421, 1.582-1.583. 
Como remedio, algunos de estos arbitristas aconsejaron reducir el valor intrínseco de la moneda aragonesa para evitar su exportación a Francia ${ }^{48}$. En su primer memorial conservado, dirigido en 1674 a la Junta Grande, el comerciante Antonio Cubero Sebastián propuso reducir el valor intrínseco del real aragonés un 25\% - de veinticuatro a dieciocho dineros- a semejanza del reino de Valencia, cuya moneda de menor peso y ley invadía Aragón. Contraria a la normativa foral, esta reforma radical no fue aceptada por parte de las instituciones aragonesas; pero la idea general siguió arraigando en los proteccionistas aragoneses. Pedro Borruel ya indicó en 1678 en su memorial a las Cortes que la calidad de la moneda aragonesa propiciaba su rápida exportación a Francia y en adelante debían fabricarse "sueldos de molinet" a imitación de Valencia, con una ley no superior a nueve dineros, y menudos jaqueses para evitar su reacuñación en Francia. José Tudela Tarazona sostenía en 1684 ante el Consejo de Aragón que la emisión de numerosos dieciochenos con este bajo valor intrínseco no sólo evitaba su importación por los franceses, sino rendía beneficios a Valencia al permitirles adquirir plata castellana y realizar transacciones comerciales en condiciones ventajosas.

Si bien las Cortes de 1677-78 adoptaron medidas firmemente proteccionistas, se limitaron a disponer las tradicionales prohibiciones de cercenar moneda aragonesa sin decidirse a alterar su peso y ley ${ }^{49}$. Sin embargo, junto al precedente marcado por las instituciones catalanas a las aragonesas en 1674 al obtener de Carlos II el derecho a rebajar el peso y ley en sus reales ${ }^{50}$, dos reformas monetarias efectuadas en la Corona de Castilla en los años ochenta reactivaron el debate entre los mercantilistas aragoneses ${ }^{51}$. La primera medida es la deflación del vellón decretada por Carlos II en febrero de 1680 para intentar reducir el fuerte

48. Sánchez Molledo, J.M., El pensamiento arbitrista..., pp. 1.345-1.346, 1.419-1.420, 1.587. Los "sueldos de molinet" que aconseja fundir Pedro Borruel en 1678 aluden a medios reales fabricados mediante el sistema del molinillo, utilizado por la ceca de Valencia junto al más habitual del cuño entre 1682 y 1686. Sobre el tema, véase Mateu, F., La ceca..., pp. 143-144.

49. Savall, P. y Penen, S., Fueros, observancias y actos de corte del reino de Aragón, Zaragoza, 1866, pp. 507-508.

50. Carrera, J., Historia de la Economía..., tomo II, pp. 363-368 y Vilar, P., Oro y moneda..., pp. 333-335. Reflejo de esta influencia, el municipio de Zaragoza adopta como modelo los privilegios monetarios disfrutados por los concejos catalanes para acuñar piezas de plata o vellón en distintas solicitudes cursadas ante Felipe IV y Carlos II para obtener la maestría de la ceca y la libertad de emisión de moneda en la segunda mitad del siglo XVII. Véase AMZ, Caja 7.777, sign. 29-4, Memorial de Zaragoza ante Felipe IV, sin fechar y Memorial de Zaragoza a Don Juan José de Austria, 20 de noviembre de 1674 y ACA, CA, legajo 71, Solicitud de la maestría de la ceca por el municipio de Zaragoza, 27 de marzo de 1674 y legajo 39, Solicitud de la maestría de la ceca por el municipio de Zaragoza, 9 de febrero de 1677.

51. Hamilton, E.J., Guerra y precios en España, 1651-1800, Madrid, 1986, pp. 49-51; Domínguez Ortíz, A., Crisis y decadencia en la España de los Austrias, Barcelona, 1973, pp. 206-217; Sánchez Belén. J.A., "Arbitrismo y reforma monetaria en tiempos de Carlos II", Espacio, Tiempo y Forma, IV, V, (1992), pp. 151-171; Collantes, E. y Merino, J.P., "Alteraciones al sistema monetario...", p. 82 y Santiago Fernández, J., Política monetaria..., pp. 201-248. 
agio que provocaba sobre la moneda de plata. Según afirmó el municipio de Zaragoza en 1683 y Manuel Lasheras en 1684, esta decisión habría venido acompañada en Castilla por la emisión subrepticia de reales y medios reales cortos de peso. Calculado éste en cincuenta y un granos más un quinto para el real casteIlano tras ser rebajado en un $16,65 \%$, su nuevo valor intrínseco equivalente a veinte dineros jaqueses fue un referente continuo desde 1680 para autores como Azores y Lasheras al pretender homogeneizar la moneda nativa de plata con las piezas acuñadas en Castilla y otros territorios anexos ${ }^{52}$. La segunda reforma fue la devaluación del real castellano en un 25\% dictada en octubre de 1686 al decidir Carlos II mantener su ley, pero rebajar su peso de forma explícita: los reales resultantes de acuñar un marco de plata en Castilla aumentaron desde 67 hasta 84, en la medida aproximada aconsejada por los arbitristas Tomás de Cardona y Alonso de Carranza ya a principios de siglo XVII53. Esta reforma se hizo extensible a toda la plata emitida en la España peninsular.

Con estos precedentes, la convocatoria y celebración de Cortes en 1684-86 permitió replantear la política monetaria al desencadenar una fuerte discusión entre los pensadores económicos aragoneses sobre el mantenimiento de la política proteccionista dictada en 1677-78, que se estaba revelando ineficaz para reactivar la economía. Este debate se ejemplifica en la publicación casi simultánea en 1684 de dos escritos dirigidos a los brazos de Cortes: Ios "Discursos históricos políticos" de Diego José Dormer en defensa de la libertad comercial y la "Exhortación a los aragoneses", como respuesta de José Gracián Serrano bajo el pseudónimo de Marcelo Nabacuchi a favor del proteccionismo ${ }^{54}$. Si bien la legislación proteccionista de 1677-78 fue derogada, las Cortes no modificaron el valor intrínseco de la moneda aragonesa ni solicitaron de la monarquía nuevas emisiones. La misma discusión sobre los problemas derivados de la devaluación del real castellano en octubre de 1686 fue delegada en una Junta de Brazos que realizó consultas en 1686-87 sin adoptar una solución definitiva.

Con motivo de este debate y el propósito de explicar la salida de metales preciosos de Aragón, Manuel de Lasheras expuso en abril de 1684 ante la Jun-

52. Archivo Histórico Nacional, CA, legajo 51.361, no 1 y Biblioteca Universitaria de Zaragoza, Caja 92-2425 Ar. La trascripción de estos documentos, en Sánchez Molledo, J.M., El pensamiento arbitrista..., pp. 1.076-1.098.

53. Vilar, J., "Una pauta del pensamiento monetarista castellano: la proposición Cardona (1618-1628)", Otazu, (ed.), Dinero y crédito (siglos XVI al XIX), Madrid, 1978, p. 451.

54. Dormer, D.J.: Discursos históricos políticos sobre lo que se ofrece tratar en la Junta de los Ilustrísimos Quatro braços del reino de Aragón, de los Eclesiásticos, Nobles, Caballeros e Hidalgos, y de las Universidades, que el Rey nuestro Señor Don Carlos Segundo ha mandado congregar este año de 1684 en la Ciudad de Zaragoça conforme lo dispuesto por su Majestad en las Cortes de 1678, Zaragoza, 1684, (edición facsímil, Zaragoza, 1989) y Sánchez Molledo, J.M., El pensamiento arbitrista..., pp. 1.482-1.518. Para un análisis de los principales economistas que intervinieron en este debate, Sánchez Molledo, J.M., "Pensamiento aragonés sobre el comercio exterior en el siglo XVII: los arbitristas", Cuadernos aragoneses de economía, 8/1, (1998), pp. 68-72. 
ta de cuatro brazos de las Cortes sus "Memorias históricas sobre el valor de la plata y oro", impresas en mayo ${ }^{55}$. Tras desestimar razones apuntadas por anteriores mercantilistas como Miguel de la Balsa -los servicios y contribuciones militares al monarca o los sufragios eclesiásticos a Roma-, Lasheras desatendió incluso el desequilibrio de la balanza comercial que había centrado el pensamiento económico aragonés durante la centuria. Por el contrario, enfatizó como causa principal de la fuga de oro y plata el mayor valor intrínseco de las piezas aragonesas y castellanas respecto a las fabricadas en otros países. Seguida por Francia, Italia e Inglaterra, Holanda habría iniciado esta apreciación en 1548 al reducir el peso a la vez que mantenía el valor nominal de la moneda de calidad y al aceptar un señoreaje de un 20\% -dividido por mitad entre el príncipe y la casa de la moneda- frente al 10\% usual en los distintos territorios de España. Estimada en un 80\% entre 1548 y 1684, la progresiva apreciación de la plata beneficiaba a estos países en sus tratos comerciales, les permitía acumularla gracias a su conversión en moneda de más baja ley y facilitaba su exportación desde España.

Frente a autores como Juan de Mariana, quienes atribuían la apreciación del oro y la plata en esencia a las fuertes emisiones y devaluaciones del vellón realizadas por la monarquía en la Corona de Castilla desde principios del siglo XVII, Lasheras se hallaba más próximo a Tomás de Cardona y Alonso de Carranza al conferir mayor importancia a la infravaloración del oro y la plata en pasta y moneda que a las modestas acuñaciones de menudos realizadas en Aragón durante el Seiscientos o a las continuas invasiones de vellón forastero de menor peso y ley ${ }^{56}$. Por este motivo, al igual que obraron diversos arbitristas castellanos desde inicios del reinado de Carlos II y con especial énfasis en 1677-84 (Francisco Centani, Sebastián Muñoz, Antonio Somoza, Juan Sánchez, Juan de Arizmendi, Pedro de la Maza), coincidía con ambos autores en proponer aumentar el valor nominal de la plata y oro monetizado para evitar su exportación. Lasheras cifraba este aumento en un $17,65 \%$ para los reales aragoneses -de diecisiete a veinte sueldos por onza- y en un $18,75 \%$-de dieciséis a diecinueve sueldos por onza- para la pla-

55. Biblioteca Universitaria de Zaragoza, Caja 92-2.425 Ar. y Biblioteca Nacional, Manuscrito 129, no 129, fols. 616-619. La exposición de las ideas de Lasheras ante la Junta de cuatro brazos de las Cortes aragonesas se documenta en ADZ, Manuscrito 580, 19 de abril de 1684, fols. 37r y 39r. Sobre este autor, Herranz, C., "Estudio crítico...", p. 152; Carrera, J., Historia de la Economía..., tomo II, pp. 471-475 y Sánchez Molledo, J.M., El pensamiento arbitrista..., pp. 1082-1098.

56. El debate monetario en Castilla en los siglos XVI y XVII, en Grice-Hutchinson, M., EI pensamiento económico en España (1177-1740), Barcelona, 1982, pp. 203-210; González, M.J., "Perfil del pensamiento monetario español en los siglos XVI y XVII", Revista de economía aplicada e historia económica, 3, (1993), pp. 32-37 y Perdices, L. y Reeder, J., El mercantilismo..., pp.102-110. Sobre los principales arbitristas sobre la materia durante el Seiscientos, García Guerra, E.M., Moneda y arbitrios. Consideraciones del siglo XVII, Madrid, 2003, Sánchez Belén. J.A. "Arbitrismo y reforma monetaria...", pp. 135-175 y Santiago Fernández, J., Política monetaria..., pp. 95-109, 232-236. 
ta en pasta, de menor ley ${ }^{57}$. Consciente como Cubero Sebastián y Gracián Serrano de la apreciación del oro frente a la plata en Aragón en la segunda mitad del $\operatorname{sigl}^{58}$, aconsejó acrecentar el valor nominal del escudo en un 28,57\%, desde veintiocho hasta treinta y seis sueldos. Toda la moneda de calidad circulante sería recogida para su reacuñación mediante el abono a sus dueños en la fábrica de dieciocho sueldos por onza de plata y setenta por doblón de oro, proceso que permitiría eliminar las piezas adulteradas. Al margen del menor peso y ley de las emisiones valencianas y catalanas, Lasheras señaló en defensa de la reforma que los reales recién labrados en Castilla sólo retenían un valor intrínseco equivalente a veinte dineros jaqueses, circulaban por Aragón y darían lugar a su falsificación en Francia para introducirlos en el reino y adquirir plata en pasta si las autoridades no procedían a su devaluación.

Como medio de generar el consenso político necesario para llevar a efecto su propuesta, Lasheras recomendaba repartir el aumento del útil derivado de la devaluación de la plata entre la hacienda real y la Diputación. Claro perjudicado, al municipio de Zaragoza sólo consideró concederle una pequeña compensación por poseer la maestría de la ceca en los dos impresos complementarios luego analizados. En una apuesta por la línea librecambista que triunfó en las Cortes de 1684-86, estimaba que el útil en poder del reino podía utilizarse en cancelar las deudas contraídas por la Diputación bajo la forma de censales para posibilitar la derogación de los derechos de aduanas y peajes disfrutados por esta institución. De igual modo, permitiría labrar reales cortos de peso similares a los castellanos no sólo para sustituir a las piezas nativas adulteradas en circulación, sino para homogeneizar el valor intrínseco de las monedas aragonesas de plata con las acuñadas en Cataluña, Valencia y Castilla, evitar así su atesoramiento o la fuga del reino y facilitar los intercambios comerciales con todos estos territorios.

Un capítulo adicional "Dudas que pueden ofrecerse contra el importante medio de subir el valor a la plata y oro en pasta y moneda", incluido en una segunda edición del anterior impreso, permitió a Lasheras rebatir previsibles objeciones a sus reformas ${ }^{59}$. El posible ascenso de precios en las mercancías extranjeras en el reino tras efectuarse la devaluación favorecería el aumento de las exportaciones aragonesas de materias primas y frenaría la fuga de moneda nativa de oro y plata al aproximarse su valor intrínseco al de las piezas acuñadas en los territorios vecinos. Al margen de la capacidad pública de tasar los precios para evitar aumentos abusivos de los artículos, la capacidad adquisitiva de la población se veía compensada de la devaluación efectuada ante la mayor

57. Sánchez Molledo, J.M., El pensamiento arbitrista..., pp. 1.090-1.094.

58. Asso, I. de, Historia..., p. 279 y Sánchez Molledo, J.M., El pensamiento arbitrista..., p. 1.345 .

59. Sánchez Molledo, J.M., El pensamiento arbitrista..., pp. 1.094-1.098. La atribución a Manuel Lasheras de las ideas recogidas en la segunda edición ampliada de este impreso es defendida ya en Carrera, J., Historia de la Economía..., tomo II, p. 474. 
liquidez reinante y la prevista derogación de los peajes y aranceles aragoneses. La disminución del valor intrínseco en los nuevos reales aragoneses a veinte dineros es justificada por su adopción en Castilla y Cataluña, y su rebaja a menos de dieciocho dineros en Valencia. A diferencia de su actividad esporádica anterior, que había limitado mucho la moneda nativa disponible, la creación de una ceca permanente en Aragón debía garantizar la continuidad de las acuñaciones de piezas de oro y plata necesarias para el comercio.

Un segundo impreso anónimo, redactado en torno a 1684 y atribuible por sus características a Manuel Lasheras, cierra las aportaciones conocidas de este autor $^{60}$. Este impreso se compone de dos fragmentos. En las "Dudas en el medio de subir el valor de la moneda y razones con que se satisfacen", Lasheras repitió los argumentos expuestos en el capítulo adicional de la segunda edición del impreso anterior tras invertir su orden. En el "Nuevo motivo para la ejecución del medio de subir el valor a la moneda" retomó ideas de Tomás de Cardona y Alonso Carranza para reforzar sus planteamientos. Tras definir los conceptos de valor extrínseco e intrínseco, consideraba que la identidad de ambos observada en la moneda de plata y oro en España resultaba perjudicial. El motivo era que su valor nominal no contemplaba en su justa medida gastos ligados a la consideración del oro y plata en barras como mercancía: los de su fabricación y, en especial, su transporte desde América. Los cálculos de estos costes reproducen sin citarlas las estimaciones efectuadas por Tomás de Cardona a principios del siglo XVII ${ }^{61}$. En la línea avanzada por Carranza y Cardona, Lasheras dedujo que la infravaloración de estos metales preciosos en España facilitaba la importación de mercancías extranjeras, el declive industrial y la despoblación, así como la exportación de oro y plata a otros territorios -con frecuencia, reinos enemigos- de manos de sus comerciantes para su acuñación con menor peso y ley. En consecuencia, se imponía imitar a los países extranjeros y subir el valor del oro y la plata tanto en pasta como en moneda.

En este caldo de cultivo, arbitristas como Miguel Azores y Martín Ezpeleta aportan una aproximación más práctica a la reducción de la ley o el peso de la moneda aconsejada por los mercantilistas aragoneses de signo proteccionista para evitar su fuga y la entrada de piezas forasteras en el reino. Característica propia, sus memoriales ante las instituciones públicas encierran una clara fina-

60. Sánchez Molledo, J.M., El pensamiento arbitrista..., pp. 273-276 y 1.099-1.105. Este documento se halla en la Biblioteca Nacional, Manuscrito 6.384, no 129 , fol. 524-527. Sin reparar en sus fuertes semejanzas de pensamiento y estilo con el anterior impreso de Manuel Lasheras, tras fecharlo en torno a 1684, Sánchez Molledo se limita a señalar el carácter anónimo de este segundo impreso.

61. Sánchez Molledo, J.M., El pensamiento arbitrista..., p. 1.103. Los argumentos expuestos por Tomás de Cardona y Alonso Carranza durante el reinado de Felipe III sobre el coste de extracción y transporte de la plata desde América a España utilizados por Manuel Lasheras se recogen en Vilar, J., "Una pauta...", pp. 451, 454 y Perdices, L. y Reeder, J., El mercantilismo... p. 108. 
lidad: la obtención de una licencia real para emitir monedas aragonesas de plata y vellón. Azores era orfebre de profesión y Ezpeleta se identifica con los ciudadanos o infanzones dedicados a lucrativos negocios en Aragón. Si bien ambos defienden una mayor autarquía monetaria que fortalezca los intercambios del reino, a diferencia de otros autores mercantilistas no consideran en sus escritos los sectores productivos de la economía aragonesa ni incluyen medidas proteccionistas como Cubero y Borruel o librecambistas como Lasheras para evitar el déficit comercial. Con un mayor conocimiento de los costes de acuñación en Aragón y de las reformas monetarias aplicadas en Castilla, Cataluña y Valencia, Azores y Ezpeleta no proponen cambios legislativos permanentes ante las Cortes sino ofertan a título personal a los poderes públicos aragoneses y al monarca un acuerdo concreto y temporal para emitir moneda. Su fuerte carácter pragmático les lleva a tener presentes las dificultades derivadas del marco legal e institucional propio del reino, así como las disputas existentes sobre los derechos de acuñación. Muestra de esta percepción, sus peticiones incluyen siempre la entrega de compensaciones en dinero tanto a la hacienda real como a la ciudad de Zaragoza, erigida desde 1677 en maestra perpetua de la ceca.

De entre ambos arbitristas, Miguel Azores destaca por su insistencia ante las instituciones públicas aragonesas y su empeño en salvar los impedimentos legales a sus propuestas ${ }^{62}$. En mayo de 1680 su petición de reducir un 16,65\% el peso del real de plata -de veinticuatro a veinte dineros- manteniendo la ley de Castilla fue rechazada por el Consejo de Aragón al considerarla opuesta a la normativa foral. En marzo de 1681 justificó ante el Consejo su propuesta de labrar 100.000 marcos de plata rebajados de peso con los precedentes catalán y valenciano: si el Principado había obtenido licencia de la monarquía para acuñar el real a la ley de once dineros usual en Castilla y Aragón pero con dieciséis dineros de peso, Valencia fabricaba sus dieciochenos con una ley de diez dineros y peso de catorce dineros. En otro memorial, adujo que esta reforma del real evitaría su extracción del reino por mercaderes castellanos, navarros, valencianos y catalanes. Su propuesta interesó al municipio de Zaragoza, ávido de beneficiarse de los derechos de emisión. Tras solicitar de Carlos II el privilegio perpetuo de emitir moneda en marzo de 1682 y mayo de $1683^{63}$, el concejo

62. ACA, CA, legajo 91, Dictamen del Consejo de Aragón sobre la petición de Miguel Azores, 27 de mayo de 1680, Memoriales de Miguel Azores, marzo de 1681 y sin fechar. La reiteración de los argumentos y el carácter monotemático de éstos y otros memoriales posteriores presentados por Miguel Azores ante el Consejo de Aragón son rasgos comunes a muchos escritos mercantilistas. Véase Perdices, L. y Reeder, J., El mercantilismo..., pp. 16-20.

63. ACA, CA, legajo 161, Solicitud de la ciudad de Zaragoza, 11 de febrero de 1682 y legajo 91, Solicitudes de la ciudad de Zaragoza, 3 de marzo de 1682, 11 de mayo de 1683 y Archivo Histórico Nacional, CA, legajo 51.361, no 1 . La licencia requerida por el municipio zaragozano en julio de 1683 de acuñar monedas de plata aragonesas según el modelo diseñado por Miguel Azores es transcrita en Sánchez Molledo, J.M., El pensamiento arbitrista..., pp. 1.076-1.081. 
remitió en julio de 1683 una solicitud de acuñar 100.000 marcos de reales de plata con estas características y semejantes a los recién acuñados en Castilla con el fin de dinamizar el comercio, evitar la extracción de moneda nativa por comerciantes forasteros y frenar la invasión de dieciochenos y ramillos valencianos. Tras su requerimiento por el Consejo de Aragón, la Diputación consultó ese año a sus abogados si la legislación foral permitía reducir el peso del real a veinte dineros, quienes desaconsejaron en agosto la medida y propiciaron así su rechazo final por parte del Consejo ${ }^{64}$. Miguel Azores reiteró su propuesta inicial al Consejo de Aragón en junio y noviembre de 1684. En mayo de 1685, sometió al examen de un orfebre dos modelos de piezas de plata con un peso de veinte y veintiún dineros ante el virrey de Aragón con vistas a la remisión del informe preceptivo a esta institución ${ }^{65}$.

La petición del Consejo de Aragón en junio de 1685 de nuevos informes a la comisión encargada del tema, la Diputación y el municipio de Zaragoza desvela la razón del fracaso de estos proyectos: su rechazo por parte de los abogados consultados por la Diputación, como obraron ese año al considerar inaceptable esta reducción en el peso sin ser refrendada por parte de las Cortes aragonesas. Ante esta objeción, Azores suplicó al Consejo de Aragón en distintos escritos que fuese tratada la materia por las Cortes antes de su finalización, a la vez que ofertó en otros memoriales sus condiciones para acuñar reales con cualquiera de los dos pesos ${ }^{66}$. Estos últimos escritos, remitidos al Consejo en abril y mayo de 1686, se hallan acompañados de unos anónimos "Discursos forales y políticos", que incluían opiniones comunes entre los defensores de la emisión de reales con menor valor intrínseco: la conveniencia de homogeneizar la moneda de plata aragonesa con la catalana y valenciana para frenar la irrupción de dieciochenos y su falsificación por parte de franceses, la necesidad de moneda del momento y la posibilidad de alterar las leyes sobre acuñación -en especial, en los menudos- según la coyuntura. Tras defender la potestad real para dictar las normas de emisión con total independencia, el fuerte debate desatado al respecto por la Diputación movió a su autor a recomendar al monarca obtener el consentimiento previo de las Cortes.

64. Biblioteca Moncayo, H-6-256. La oposición de la Diputación al proyecto de Azores en agosto de 1683 se constata en Asso, I. de, Historia..., pp. 278-279 y Sánchez Molledo, J.M., EI pensamiento arbitrista..., pp. 1.070-1.075.

65. ACA, CA, legajo 195, Memorial de Miguel Azores al Consejo de Aragón, 28 de mayo de 1684 y legajo 91, Memorial de Miguel Azores, 21 de noviembre de 1684 e Informe del Virrey, duque de Híjar, sobre el ensayo de Miguel Azores, 29 de mayo de 1685.

66. ACA, CA, legajo 91, Memoriales de Miguel Azores al Consejo de Aragón, 9 de julio de 1685, sin fechar, 23 de abril de 1686 y Memorial anónimo titulado Discursos forales y políticos sobre si fabricar moneda de plata en Aragón de la ley de Castilla y pesso de veynte y un dinero cada real será de la conveniencia pública de aquel Reyno y en que forma sea en contrario dicha fábrica con sus disposiciones forales, examinado por el Consejo de Aragón el 26 de abril de 1686. 
Pese a la falta de resolución de las Cortes de 1684-86 sobre esta materia, la devaluación de la moneda de plata castellana realizada por Carlos II en octubre de 1686 impulsó a Azores a realizar una propuesta más radical en 1688 ante el Consejo de Aragón, quien solicitó informes a la Audiencia y al municipio de Zaragoza ${ }^{67}$. En primer lugar, propugnó reducir un 25\% el peso del real aragonés, hasta dieciocho dineros, para adaptarlo al nuevo valor intrínseco del real castellano. En segundo término, rebajar la ley de los menudos al suprimir un $38^{\prime} 8 \%$ de su anterior contenido en plata y añadir dos onzas de cobre con el fin de sustituir las piezas anteriores por otras de menor valor intrínseco. El municipio de Zaragoza apoyó la propuesta al solicitar en julio de 1688 al Consejo de Aragón licencia para labrar moneda y remitirle un dictamen favorable a igualar la ley y peso de las piezas aragonesas con las de Castilla, Cataluña y Valencia para homogeneizar el comercio entre estos reinos ${ }^{68}$. Tras exponer el mayor valor intrínseco de las piezas de plata y oro españolas frente a las extranjeras, este informe recogía otros argumentos de Manuel Lasheras para devaluar la moneda: propiciar el desarrollo comercial al aumentar la liquidez, promover la industria al favorecer su competitividad mediante el previsible ascenso de precio de las mercancías extranjeras y evitar la fuga de moneda nativa de calidad y la invasión de piezas foráneas de menor valor intrínseco. Por el contrario, los abogados de la Diputación desaconsejaron en 1689 la reforma y estimaron más útil recurrir a la mera prohibición de usar moneda forastera para detener la fuerte irrupción de piezas valencianas detectada en el reino ${ }^{69}$. Dos "Discursos jurídico-políticos" publicados ese año, firmados por la Diputación y José Francisco Arpayón y Torres, reiteraron el concurso de esta institución en toda emisión de moneda y la obligación de mantener el peso y la ley dispuestos por los fueros. Una última solicitud documentada de Azores en julio de 1691 para acuñar reales de plata con la ley y el peso de Castilla se vio abocada por este desacuerdo institucional al fracaso ${ }^{70}$.

67. Asso, I. de, Historia..., pp. 282-283.

68. ACA, CA, legajo 91, Peticiones de la ciudad de Zaragoza, 13 de julio de 1688, Informe de Don Felipe Bardají, 3 de agosto de 1688 y Archivo Histórico Nacional, CA, legajo 51.361, Dictamen de los jurados de Zaragoza sobre la fabricación de moneda en Aragón, 31 de agosto de 1688.

69. ACA, CA, legajo 91, Memorial titulado Consultación jurídica y foral de los Ilustrísimos señores Diputados del Reyno de Aragón a sus abogados ordinarios sobre si pueden y deben prohibir el curso de la moneda estrangera de dineros ramilletes que se ha introducido en el reyno, 18 de abril de 1689. La oposición de la Diputación a toda innovación monetaria en 1689 es destacada en Carrera, J., Historia de la Economía... tomo II, pp. 476-478; Mateu, F., "El sistema monetario...", p.127 y Sánchez Molledo, J.M., El pensamiento arbitrista..., pp. 272-273. Sobre la penetración de moneda valenciana en Aragón ese mismo año, ADZ, Manuscrito 594, 22 de abril de 1689, fol. 722r-723r.

70. ACA, CA, legajo 91, Carta de la Diputación sobre el memorial de Azores, 10 de julio de 1691, Carta del municipio sobre el memorial de Azores, 3 de julio de 1691. 
Frente a los numerosos memoriales de Miguel Azores, Martín Ezpeleta redactó en noviembre de 1692 una propuesta conjunta de acuñación de moneda aragonesa y arriendo de los derechos aduaneros del reino entre 1693 y 1695. Su petición enlaza con las quejas de anteriores arrendatarios como Francisco Sanz de Cortes sobre las pérdidas ocasionadas al negocio por la penetración de vellón catalán y valenciano en Aragón al dificultar el comercio y provocar la fuga de la moneda de plata ${ }^{71}$. Tras la devaluación de los reales castellanos efectuada en 1686, en atención a los obstáculos legales y la fuerte oposición de la Diputación a rebajar el valor intrínseco de la moneda de plata, Ezpeleta decidió preservar el peso y la ley de Castilla en los 50.000 marcos de reales y medios reales aragoneses que solicitó acuñar ${ }^{72}$. Por el contrario, le pareció más factible reducir el valor intrínseco en la emisión de menudos no sólo por tratarse de moneda de vellón, sino por contar esta medida con precedentes en Aragón durante el Seiscientos: si su ley fue rebajada en 1611-18 de forma excepcional, la reducción de su peso practicada en estos años fue mantenida en 1655-57 y 1677-80. Ezpeleta propuso mantener en los 200.000 marcos de vellón que pidió fabricar el peso adoptado en 1611-18, pero rebajar su ley. La fineza del vellón confirmada en 1655-57 y 1677-80, fijada en un dinero y doce granos, se reduciría en un 50\% hasta suponer sólo dieciocho granos: el vellón perdía así valor intrínseco en mayor medida que la aconsejada por Azores en 1688. Con objeto de facilitar los intercambios comerciales, Ezpeleta asumía fundir todos los dineros aragoneses anteriores a esta emisión y ceder un agio del $3 \%$ a los particulares que los depositasen en la ceca de Zaragoza para su acuñación con la nueva ley.

Consciente de su oposición, Ezpeleta defendió con mayor vigor la rebaja de la ley del vellón en la copia modificada de su propuesta remitida a la Diputación ${ }^{73}$. Su argumento esencial era conseguir su retención en el reino, donde ya sólo se hallaban dineros correspondientes a la última acuñación, efectuada por el concejo de Zaragoza en 1677-80. Como referencia, indicó que la rebaja de la ley de los ardites efectuada por el concejo de Barcelona en el siglo XVII hasta retener sólo un 41,6\% del contenido en plata que guardaban las emisiones realizadas bajo Carlos I había impedido una exportación significativa del Principado por su escaso valor intrínseco ${ }^{74}$. La fuerte invasión de ramillos a fines de la centuria, sobre todo en el sur de Aragón y su capital, había hecho sospechar que los menudos aragoneses eran extraídos del reino para ser convertidos en Valencia en ramillos de menor ley y obtener así notables ganancias. Por el con-

71. ACA, CA, legajo 48, Memorial de Francisco Sanz de Cortes, sin fechar.

72. ACA, CA, legajo 59, Memorial de Martín Ezpeleta, 8 de noviembre de 1692.

73. ACA, CA, legajo 59, Memorial de Martín Ezpeleta, copia modificada entregada a la Diputación, sin fechar y adjuntada al anterior para su remisión por el virrey, 11 de noviembre de 1692.

74. Carrera, J., Historia de la Economía..., tomo II, pp. 259-262, 360-361, 363-368, 478479 y Vilar, P., Oro y moneda..., pp. 332-335. 
trario, la defensa de la emisión de reales y medios reales con la ley y el peso de Castilla resultaba muy difícil al no permitir evitar su exportación del reino hacia Francia ni la permanente invasión de dieciochenos. En consecuencia, fue expuesta por Ezpeleta ante la Diputación como una actividad secundaria y susceptible de supresión dentro de su propuesta, que daría prioridad a la acuñación de vellón. Pendientes estos memoriales de examen por parte de la Real Audiencia y la Diputación, la urgencia de arrendar las aduanas aragonesas unida a la falta de consenso institucional percibida sobre las normas de acuñación monetaria por adoptar en el reino llevó al Consejo de Aragón a desestimar con rapidez el arriendo conjunto de ambos negocios propuesto por Ezpeleta.

De forma sintomática, a la par que cesan las solicitudes al monarca de permiso para acuñar plata o vellón por parte del municipio de Zaragoza, el arbitrismo monetario se agota en Aragón a principios de los años noventa del siglo XVII. Como causas principales, los esfuerzos efectuados en la década anterior habían revelado la oposición frontal de la Diputación y el desinterés de la monarquía ante estos proyectos. La ausencia de nuevas convocatorias de Cortes en Aragón privó a los arbitristas del único foro reconocido por los organismos públicos para salvar los obstáculos legales e institucionales a las reformas solicitadas. De hecho, la celebración de las últimas Cortes aragonesas de la época foral moderna aún permitió al brazo de caballeros e hidalgos elevar en 1702 una petición de fabricar reales y dineros devaluados para conseguir una mayor aproximación al valor intrínseco de las monedas valencianas y catalanas; pero de nuevo sin éxito ${ }^{75}$.

Resultado del fracaso de las reformas monetarias más acertadas expuestas por los mercantilistas aragoneses, la escasez de piezas nativas, las dificultades de equiparar monedas de distinta procedencia y otros problemas de circulación presentes en el siglo XVII se perpetuaron en Aragón el resto de la Edad Moderna. Frente a la percepción "autocentrada" adoptada por particulares e instituciones del reino en el Seiscientos, la política monetaria de la monarquía borbónica durante el siglo XVIII mostró un claro avance de su concepción estatal en las soluciones planteadas a estos problemas. Así, si bien asumió consideraciones de estos arbitristas al emitir menudos en el reino en 1710-19 para proceder a su devaluación en 1718, obvió realizar nuevas acuñaciones de moneda aragonesa ${ }^{76}$. Por el contrario, inició un lento proceso de homogeneización entre todas las piezas

75. Borras, G., La Guerra de Sucesión en Zaragoza, Zaragoza, 1972, pp. 27-28, 117-121. Si bien se defendió una devaluación del real aragonés similar a la practicada en el dieciocheno acuñado en Valencia, la rebaja propuesta de la ley del dinero en un 50\% -idéntica a la requerida por Martín Ezpeleta en 1692- le permitía preservar un valor intrínseco superior al del ardite catalán y ramillo valenciano.

76. Asso, I. de, Historia..., pp. 282-284; Redondo, G., "Numismática aragonesa...", pp. 214-215 y Sánchez García, S., "Alteraciones monetarias en Aragón durante la primera mitad del siglo XVIII", Jerónimo Zurita, 75, (2000), pp. 276-280 
fabricadas en sus territorios peninsulares con base en el sistema castellano y especial énfasis en el vellón que se propuso como fin último la eliminación de las piezas provinciales y la gestación de una moneda nacional ${ }^{77}$.

\section{Conclusiones}

Como conclusiones, con la excepción de Manuel Lasheras, se debe afirmar que el pensamiento económico aragonés abordó el problema monetario desde una perspectiva limitada. Menos desarrollado que el arbitrismo comercial, intentó ofrecer soluciones a los poderes públicos ante el declive y reestructuración de la economía y las alteraciones monetarias vigentes en el reino. Con una escasa influencia teórica de los mercantilistas castellanos, su fuerte orientación práctica y la mayor similitud de los problemas económicos e institucionales aragoneses en materia monetaria con los existentes en Cataluña y Valencia propiciaron la receptividad de las reformas aplicadas en ambos territorios durante la centuria, asumidas de forma definitiva al rebajar Carlos II el valor intrínseco de la moneda de plata castellana en la década de los años ochenta.

Junto a la evolución económica, esta línea de pensamiento respondió a intentos de las instituciones aragonesas por intervenir en el proceso de circulación monetaria para corregir fuertes alteraciones o plantear cambios en las normas de fabricación. Frente a Cataluña y Valencia, cuyos poderes públicos consiguieron aumentar sus acuñaciones de plata y vellón a la vez que reducir su valor intrínseco, Aragón combinó la escasez de emisiones con modestas rebajas de su peso y ley durante el Seiscientos. La falta de consenso institucional, las dificultades impuestas por la normativa foral y el desinterés de la monarquía hacia las reformas propuestas por los arbitristas impidieron afirmar una política monetaria autónoma en el reino, perpetuaron la escasez de piezas nativas y otros problemas monetarios ya existentes en el siglo XVII para el resto de la Edad Moderna. Su resolución vendrá cada vez más supeditada durante el Setecientos a las directrices del Estado borbónico, orientadas a homogeneizar las distintas acuñaciones realizadas en la España peninsular con especial énfasis en el vellón para intentar extinguir por último las piezas provinciales en aras de crear una moneda nacional.

Objeto de una larga gestación, el ideario económico sobre circulación monetaria asume en Aragón tanto el fuerte enfrentamiento institucional por su control como la reestructuración de su economía hacia una mayor extroversión

77. Tras los intentos de homogeneizar el vellón peninsular durante el reinado de Felipe $\mathrm{V}$, el proyecto más decidido de extinguir monedas provinciales en el Noreste peninsular por parte del Estado borbónico se efectuó bajo Carlos III en 1777, sin culminarse de forma definitiva. Véase Mateos, J.A., "Política económica y alteraciones monetarias en Aragón durante el reinado de Carlos III (1759-1788)", Josep Fontana. História i projecte social. Reconeixement a una trajectoria. Barcelona, 2004, vol. I, pp. 289-295. 
en el Seiscientos. Junto a numerosas reflexiones de corte tradicional, la emergencia de problemas monetarios en la primera mitad de siglo permitió a algunos arbitristas -Jerónimo Ardid, Miguel de la Balsa- indagar sus causas; pero sus medidas destinadas a evitar la exportación de oro y plata adolecieron de cierta simplicidad y no contemplaron reformar las normas de acuñación. Inserto en una discusión más amplia sobre la política económica del reino, el debate monetario eclosionó en torno a las Cortes de 1677-78 y 1684-86 y asumió como tema central la reducción del valor intrínseco de las nuevas acuñaciones. Supeditada a su política comercial, los escritores proteccionistas apoyaron esta rebaja a imitación de Valencia desde mediados de los años setenta para evitar la fuga de plata, planteamiento reforzado por Azores y Ezpeleta en 1680-92 con referencias a emisiones castellanas, catalanas y valencianas. Desde una óptica más favorable al librecambio, tras asumir la dimensión de las reformas monetarias de Carlos II y el ideario de Carranza y Cardona, Lasheras defendió en 1684 una devaluación de la moneda de plata y oro aragonesa que homogeneizase su valor intrínseco con el de las piezas acuñadas en territorios vecinos, facilitase las transacciones interiores y aumentase las exportaciones para corregir el déficit comercial. Por último, pese a la mayor elaboración de las propuestas monetarias mercantilistas entre 1674 y 1692, su adaptación a la estructura política y evolución económica del reino fue insuficiente para salvar los obstáculos institucionales, motivo que provocó el declive de este ideario en los últimos años de la época foral moderna. 